\title{
Fluctuating dental asymmetry in rabbits with familial nonsyndromic
}

\author{
coronal suture synostosis \\ ${ }^{1}$ Oro-Maxillo-Facial Surgeon, Private Practice, Charleston WV \\ ${ }^{2}$ University of Pittsburgh, School of Dental Medicine \\ ${ }^{3}$ University of Pittsburgh, Department of Plastic Surgery
}

Mae A. Hyre ${ }^{1}$, Seth M. Weinberg ${ }^{2}$, Gregory M. Cooper ${ }^{3}$, James Gilbert ${ }^{3}$, Michael I. Siegel ${ }^{2}$, Mark P. Mooney ${ }^{2}$

\section{Abstract}

Fluctuating dental asymmetry has been linked to conditions of unstable pre- and peri-natal development. Familial, nonsyndromic craniosynostosis disrupts early craniofacial development through localized excessive calvarial ossification leading to the premature fusion of the calvarial sutures. Such abnormal gene expression may also produce systemic stress resulting in developmental instability, thereby affecting normal trait symmetry. The present study was designed to test this hypothesis by examining fluctuating dental asymmetry in an inbred strain of rabbits with familial, nonsyndromic coronal craniosynostosis. The mesiodistal (MD) and buccolingual (BL) dimensions of the right and left maxillary first molars were measured in four groups of New Zealand white rabbits $(N=176 ; n=40$ with early-onset synostosis, $n=65$ with delayed-onset synostosis, $n=46$ in-colony, phenotypically normal rabbits, and $n=25$ wild-type normal controls). For each variable, raw signed asymmetry was calculated (left-right) and tested for assumptions of fluctuating asymmetry (i.e., normality and non-directionality). Any group that did not meet these assumptions was excluded from further analysis. Using a standard size-adjusted, fluctuating asymmetry index, mean fluctuating asymmetry was calculated and compared across groups with non-parametric statistics. For the MD dimension, no significant $(p>0.05)$ group differences in mean fluctuating asymmetry were observed among groups. In contrast, rabbits with early-onset synostosis had significantly $(p<0.05)$ more fluctuating asymmetry in the BL dimension compared to wild-type controls. Results demonstrate increased fluctuating dental asymmetry in rabbits with nonsyndromic, earlyonset coronal suture synostosis and suggest that the molecular events producing suture synostosis locally may have also have systemic effects. Knowledge of these systemic interactions may contribute to a fuller understanding of the phenotypic spectrum observed in individuals with nonsyndromic craniosynostosis.
Citation: Hyre M, et al. (2017) Fluctuating dental asymmetry in rabbits with familial nonsyndromic coronal suture synostosis. Dentistry 3000.

1:a001 doi:10.5195/d3000.2017.78

Received: July 11, 2017

Accepted: August 18, 2017

Published: October 10, 2017

Copyright: C2017 Hyre M, et al. This is an open access article licensed under a Creative Commons Attribution Work 4.0 United States License.

Email: mpm4@pitt.edu

\section{Introduction}

Nonsyndromic, simple craniosynostosis is a relatively rare condition $(0.06-1.9 / 1000)$ that occurs when one or more of the calvarial sutures fuses prematurely during the period of active brain growth, resulting in aberrant patterns of growth in both the neurocranium and viscerocranium [1]. In recent years, craniofacial biologists have begun to unravel the biological pathways underlying abnormal suture morphogenesis. The emerging picture is one of complexity, involving multiple osteogenic growth factors and genes (FGFs, TGF $\beta$ s, BMPs, MSXs, etc.) operating at various levels of regulation $[2,3]$. While the genetic mutations responsible for syndromic cases of cranio- synostosis have been known for some time [4,5], only recently have specific mutations in a number of genes (FGFR3 and MSX2 for e.g.) been identified in individuals affected with nonsyndromic coronal suture synostosis [5-8]. The number of familial cases, however, remains relatively small at around $14 \%$ for coronal cases and $6 \%$ for sagittal cases $[1,9,10]$, suggesting that sporadic mutations typically are involved.

While significant progress has been made in elucidating the molecular causes of premature suture fusion, our understanding of the disease at the phenotypic level still remains incomplete. In particular, it is unclear how alterations at the genotypic level are translated into the range of varia- ble phenotypes that present under the heading nonsyndromic craniosynostosis. The presence of certain environmental exposures (e.g. cigarette smoke), systemic factors (e.g. circulating levels of thyroxin or androgens) and/or the additive effects of modifier genes may all act to modulate phenotypic severity [1]. Therefore, given a genetic predisposition for nonsyndromic craniosynostosis, the specific phenotypic outcome may depend in part on the presence of additional deleterious factors, both intrinsic and extrinsic to the organism. The presence of such factors during ontogeny may create a developmental environment characterized by amplified stress, leading to both increased synostotic severity and, possibly, other phenotypic manifesta- (cc) BY

ULIS D-Serbe
New articles in this journal are licensed under a Creative Commons Attribution 4.0 United States License.

This journal is published by the University Library System, University of Pittsburgh as part of its D-Scribe Digital Publishing Program and is cosponored by the University of Pittsburgh Press. 
tions. Unfortunately, little is known about the phenotypic correlates of nonsyndromic craniosynostosis apart from the well-documented secondary growth effects on the skull. However, because many of the growth factors involved in the regulation of suture morphogenesis have expression patterns in a variety of other tissues throughout the developing organism $[1,2-5,11,12]$ it is unlikely that the extent of the disruption in nonsyndromic craniosynostosis is limited entirely to the suture site.

Increased stress during development, either of genomic or environmental origin, has been linked to specific phenotypic patterns in organisms. One of the most commonly used phenotypic indicators of developmental stress is the degree of random asymmetry present in normally symmetrical, paired traits, commonly referred to as fluctuating asymmetry [13]. Mather [14] reasoned that because bilateral characteristics are programmed by the same genes, random deviations from symmetry will represent a phenotypic record of the level of instability present during development. Waddington $[15,16]$ used the term canalization to refer to the degree to which genetically programmed developmental processes are able to resist perturbations during ontogeny. Developmental instability can be understood as the degree to which developmental processes are unable to buffer against such perturbations, the consequences of which are manifested in the phenotype $[17,18]$.

Interest in developmental instability as a mechanism for elucidating the complex relationship between genotype and phenotype has increased dramatically over the last decade [18-20]. Importantly, elevated levels of fluctuating asymmetry have been associated with a variety of stressors during development, including a number of genetic diseases [21]. For example, there is evidence of elevated fluctuating asymmetry in humans affected with orofacial clefts [22-25], Down's syndrome [26,27], Fragile-X syndrome [28], premature birth $[29,30]$ attention deficit-

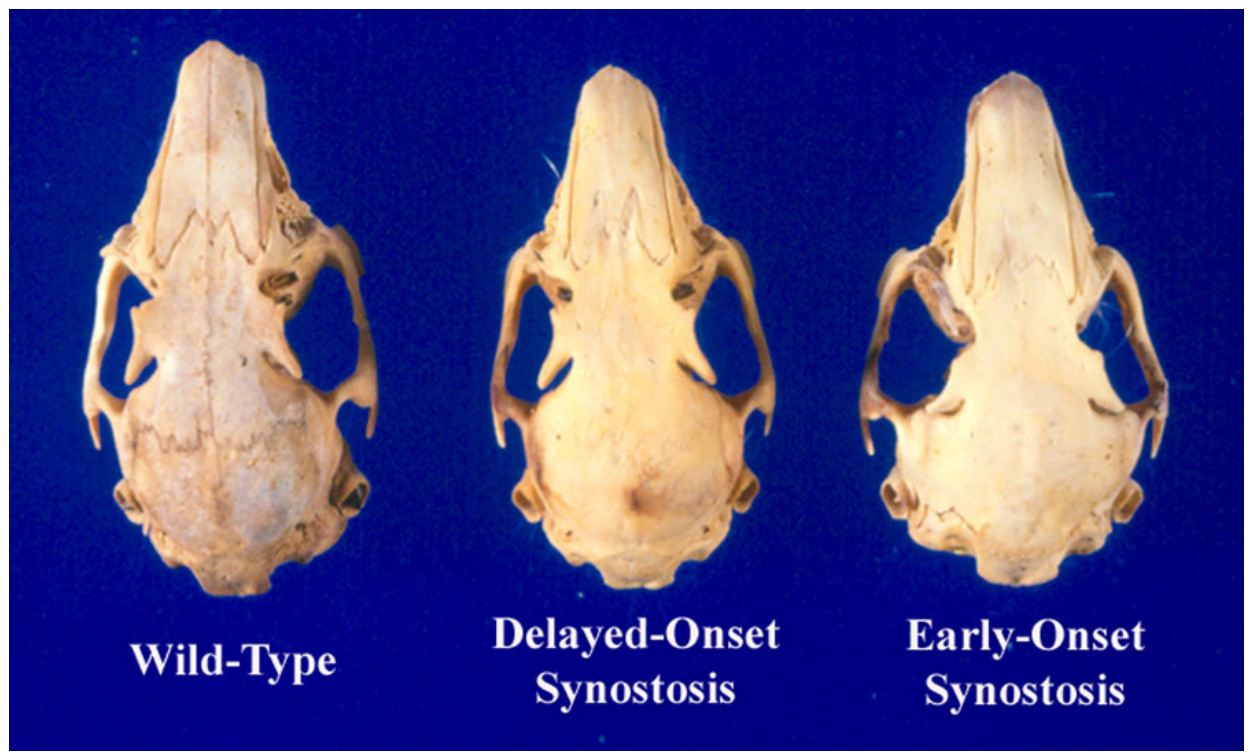

Figure 1. Superior view of skulls from a 42 day wild-type normal control rabbits and rabbits with late-onset (postnatal) and early-onset (prenatal) coronal suture synostosis. Note the shorter, wider cranial vaults in the rabbits with coronal suture synostosis compared to the wild-type rabbit skull.

hyperactivity disorder [31], generalized mental retardation [32], spinal malformation [33] and a wide range of psychiatric diseases including schizophrenia, major depression and bipolar disorder [21,34]. Because nonsyndromic craniosynostosis is a disease that disrupts craniofacial development through abnormal calvarial bone homeostasis resulting in excessive ossification and premature suture fusion [2,3,35-37], affected organisms likely experience increased systemic stress during ontogeny. In principle, such stress should manifest itself in the phenotype as elevated levels of fluctuating asymmetry. However, De Leon and Richtsmieir [38] reported little fluctuating asymmetry in the cranial vault bones of children with nonsyndromic sagittal suture synostosis and deserves further study. Given the overlap in molecular expression between calvarial suture and dental morphogenesis [39], the association between dental abnormalities and syndromic forms of craniosynostosis [40], and the fact that both syndromic and nonsyndromic cases may share a common genetic basis [5-8], it is reasonable to suspect that the teeth of nonsyndromic craniosynostotic organisms develop within a stressed physiological environment and may be a prime candidate for manifesting elevated levels of fluctuating asymmetry. In order to test the hypotheses that genomic stress is elevated in the presence of nonsyndromic craniosynostosis, and that such stress increases with the severity of the craniosynostotic phenotype, we propose to investigate patterns of fluctuating dental asymmetry in a rabbit model with variably expressed, familial, nonsyndromic, coronal suture synostosis under controlled laboratory conditions. 


\section{Materials and Methods}

\section{Study sample}

Our study sample consisted of craniodental skeletal material from 176 New Zealand White rabbits (Oryctolagus cuniculus) affected with varying degrees of familial, nonsyndromic, primary coronal suture synostosis. The rabbits were part of a unique breeding colony, established in 1993, at the University of Pittsburgh [41-46]. It has served as a useful model for the study of familial, nonsyndromic craniosynostosis in human infants [35, 41-47]. All crania were obtained from rabbits enrolled in ongoing research protocols. All protocols were reviewed and approved by the University of Pittsburgh, Institutional Animal Care and Use Committee (IACUC).

Rabbits from this colony exhibit a wide range of phenotypes, including: phenotypically normal carriers; rabbits with delayed-onset synostosis (presenting at about 42 days post-natal), and; rabbits with early-onset complete unilateral or bilateral synostosis (presenting at about 21 days of gestation) [37, 4145] (Figures 1 and 2). It has been shown recently that rabbits with early-onset coronal suture synostosis (i.e., the most severe phenotype) were the most inbred and exhibited the highest coefficients of inbreeding [46]. For the present study, dentition from the skulls of 40 rabbits with early-onset synostosis, 65 rabbits with delayed-onset synostosis, and 46 incolony, phenotypically normal rabbits were analyzed. Further, 25 wild-type rabbits of the same breed were included as a separate control group. Table 1 shows basic descriptive statistics of the sample by group. No difference in the distribution of males and females across groups was ob- served. Thus, rabbits of both sexes were pooled during analysis. Further, due to sample size limitations, bilateral and unilateral affected animals were combined for all analyses. All rabbits were housed and fed under similar laboratory conditions.

\section{Measurement procedure}

The mesiodistal (MD) and buccolingual (BL) dimensions of the right and left first maxillary molars were measured with a set of Mitotoyo digital calipers (Japan) (Figure 3). The first maxillary molar was chosen because evidence suggests it is a very stable tooth developmentally [48]. This conservative approach should bias our results against finding fluctuating asymmetry, thus minimizing the chances of reporting a false-positive. For the MD measurement, the arms of the calipers were positioned at the widest portion of the tooth at the occlusal surface (Figure 3 ). For the BL measurement, one arm of the calipers was positioned flush against the buccal edge of the tooth. With the one arm in place, the measurement was then taken across the tooth at the level just below the occlusal plane on the lingual edge (Figure 3). The BL measurement was not taken directly at the occlusal surface in order to avoid measuring the effects of functional wear. All measurements were taken by one individual (MAH).

\section{Statistical analysis}

Testing assumptions of fluctuating asymmetry:
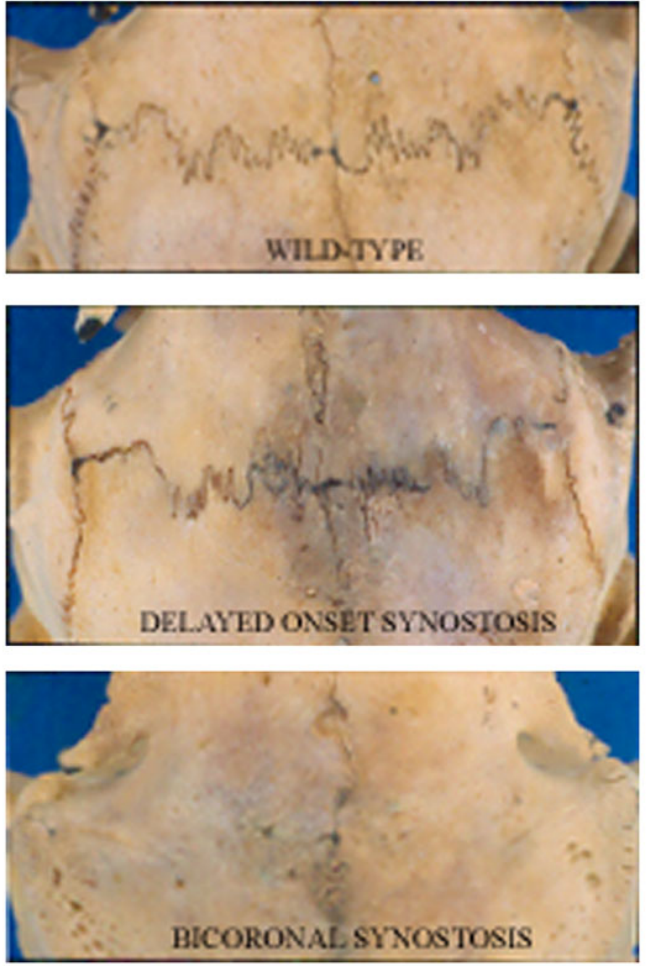

Figure 2. Superior view of the coronal suture from a 42 day wild-type normal control rabbits and rabbits with late-onset (postnatal) and early-onset (prenatal) coronal suture synostosis. Note the obliterated coronal suture in the early-onset synostosis rabbit skull (bottom picture), the dysmorphic and incomplete coronal suture in the late-onset synostosis rabbit skull (middle picture), compared to a normal coronal suture in the wild-type rabbit skull (top picture).

\section{Following standardized} methodological guidelines $[49,50]$, the statistical nature of the asymmetry was explored prior to further analysis. For fluctuating asymmetry, two conditions must be met. The raw, signed left-right difference scores must have both: 1) a normal distribution and 2) a mean equal to zero. The first assumption was tested with the Kolmogorov-Smirnov test for normality, while a one sample t-test was performed to determine whether the mean of the signed asymmetry scores is significantly different from zero. A mean significantly different from zero indicates directional asymmetry, which may have different biological 
implications than fluctuating asymmetry. Tests of fluctuating asymmetry assumptions were carried out for each variable within each group separately.

For both MD and BL variables, the phenotypically normal rabbits were the only group that failed the test of normality $(p<0.05)$. The phenotypically normal (in-colony) control group was therefore dropped from subsequent analyses. For the BL variable, mean raw asymmetry in the delayed-onset group was significantly different from zero $(t=3.869 ; \mathrm{p}<$ $0.001)$, indicating the presence of directional asymmetry. As a result, the delayed-onset group was dropped from further analysis of the BL variable.

Because random measurement error is statistically identical to fluctuating asymmetry, the degree of error present in the data must also be assessed. Repeat measurements were obtained on all 176 animals by the same observer (MAH). For each variable, measurement error was quantified by computing the mean absolute difference (MAD) from the replicate measures [51]:

Mean Absolute Difference $=\Sigma$ | Time 1 - Time 2 | / N

This value was then compared directly against the standard unsigned mean fluctuating asymmetry index:

Fluctuating asymmetry $=\Sigma$ | Left - Right | / N

If the magnitude of the mean absolute difference is determined to be less than that of mean fluctuating asymmetry for a given variable, this indicates that residual fluctuating asymmetry exists even after measurement error is taken into account. Conversely, if the mean absolute difference is greater than mean fluctuating asymmetry, then we cannot be certain that any measurable fluctuating asymmetry exists. For both variables in the present study, mean absolute difference was less than mean fluctuating asymmetry (MD: 0.05 vs. 0.07; BL: 0.04 vs. 0.09). This pattern held true both overall and within each group separately, indicating that fluctuating asymmetry was not swamped by random measurement error.

For some biological traits, increased trait size is related to elevated levels of fluctuating asymmetry. Thus, the effects of size on fluctuating asymmetry magnitude must be considered. For each variable, Pearson correlation coefficients were calculated between original trait values and unsigned FA values (| Left Right|). Because a weak but signifi- cant correlation $(r=0.20 ; p<0.01)$ was observed for the MD variable, an alternative size-adjusted FA index was used for subsequent group comparisons:

Fluctuating asymmetry $=(\mid$ Left Right | / 0.5 Left + Right)

Group fluctuating asymmetry comparisons:

Using the standard sizeadjusted index, mean fluctuating asymmetry across groups was compared using nonparametric statistics, followed by post-hoc comparisons where necessary. The nonparametric approach was employed because the fluctuating asymmetry index chosen for group comparisons converts leftright differences into absolute values, which by nature are not distributed normally. Because certain groups failed to meet the assumptions of fluctuating asymmetry, certain group comparisons could not be carried out. For the MD variable, only three

Table 1. Descriptive Statistics for the Study Sample

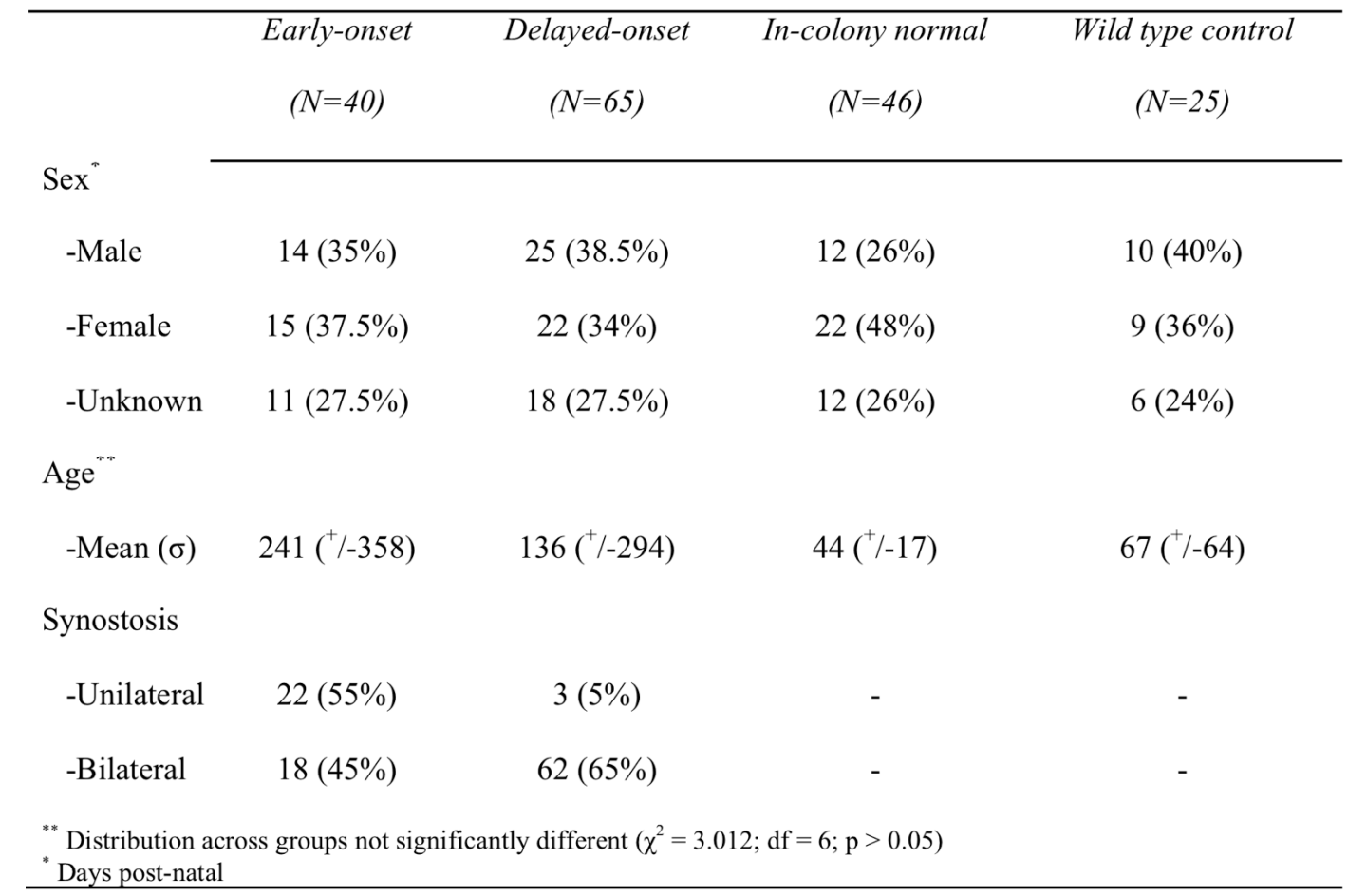


groups (early-onset, delayed-onset, and wild-type controls) were compared with a Kruskal-Wallis ANOVA. For the $\mathrm{BL}$ variable, only two groups (early-onset and wild-type controls) were compared, thus a MannWhitney $U$ t-test was used. Statistical analyses were performed with the program SPSS 11.5. All differences were considered significant if $p<$ 0.05 .

\section{Results}

For the MD dimension, rabbits with early-onset synostosis had more fluctuating asymmetry than rabbits with delayed-onset synostosis while wild-type control rabbits had a greater magnitude of fluctuating asymmetry than either affected group. However, no significant ( $p>$ 0.05 ) group differences in mean fluctuating asymmetry were observed for the MD dimension (Table 2). In contrast for the $\mathrm{BL}$ dimension, rabbits with complete early-onset synostosis had a significantly $(p<0.05)$ greater magnitude of fluctuating asymmetry than wild-type control rabbits (Table 2 ). Although mean age differed con- siderably across groups, no significant correlation $(p>0.05)$ between FA and age was observed for either tooth dimension.

\section{Discussion}

Familial, nonsyndromic craniosynostosis is a disease characterized by abnormal calvarial bone regulation early in prenatal life [2,3,35-37]. It was hypothesized that this disruption in homeostasis would lead to increased systemic physiological stress during the critical period of dentogenesis, resulting in increased fluctuating dental asymmetry. Results of the present study confirm this hypothesis; rabbits with early-onset synostosis had a significantly greater magnitude of fluctuating dental asymmetry for the $\mathrm{BL}$ dimension of the first maxillary molars compared to unaffected controls. This pattern was not observed, however, for the MD dimension. These results suggest that the teeth of rabbits with congenital nonsyndromic craniosynostosis develop within a stressed physiologi-

Table 2. Comparison of Fluctuating Asymmetry Across Groups for Each Tooth

\section{Dimension}

\begin{tabular}{|c|c|c|c|c|c|c|c|}
\hline Variable & Group & $N$ & $\begin{array}{c}\text { Mean Fluctuating } \\
\text { Asymmetry }\end{array}$ & $\sigma$ & $\begin{array}{l}\text { Mean } \\
\text { rank }\end{array}$ & $\begin{array}{l}\text { Test } \\
\text { stat }\end{array}$ & Sig. \\
\hline \multirow[t]{4}{*}{ MD } & Early-onset & 40 & 0.040 & 0.026 & 69.10 & $4.268^{*}$ & 0.118 \\
\hline & Delayed- & 65 & 0.033 & 0.024 & 59.18 & & \\
\hline & onset & & & & & & \\
\hline & Wild-type & 25 & 0.045 & 0.029 & 76.16 & & \\
\hline \multirow[t]{2}{*}{ BL } & Early-onset & 40 & 0.035 & 0.031 & 37.08 & $-2.227^{* *}$ & 0.026 \\
\hline & Wild-type & 25 & 0.021 & 0.021 & 26.48 & & \\
\hline $\begin{array}{l}{ }^{*} \text { Kruskal } \\
{ }^{* *} \text { Mann-I }\end{array}$ & $\begin{array}{l}\text { Wallis test us } \\
\text { Whitney test u }\end{array}$ & & & & & & \\
\hline
\end{tabular}

cal environment. Unfortunately, because certain groups did not satisfy the statistical requirements of fluctuating asymmetry, all group comparisons were not possible. It could not be determined, therefore, whether fluctuating asymmetry was related to craniosynostosis in a severitydependent manner. These results, although limited in scope, suggest that a broader array of primary defects may be present in individuals with nonsyndromic craniosynostosis, and that these may not be limited entirely to the suture site. In principle, a fuller understanding of the phenotypic correlates present in nonsyndromic craniosynostosis may shed light on disease etiology. For instance, predictions can be generated about patterns of phenotypic variation from the known expression patterns of specific candidate genes.

Prior to the present study, dental fluctuating asymmetry had not been examined in individuals affected with craniosynostosis. Previous research into dental development within the craniosynostoses has been focused almost entirely on syndromic forms of the disease. In Apert syndrome, for instance, a wide variety of dental anomalies have been reported; these include delayed development, ectopic teeth, hypodontia and supernumerary teeth $[52,53]$. Similarly, in cases of Crouzon syndrome, ectopic eruption, delayed development and hypodontia have all been observed [54,55,12]. Pfeiffer syndrome may be characterized by natal teeth [56], suggesting precocious dental development. This is further supported by reports of supernumerary and ectopic teeth [57]. Given the fact that FGFs play a role in both dental development and suture morphogenesis, it is perhaps not surprising that the teeth are affected in cases of syn- 
dromic craniosynostosis $[39,11,58]$. In light of this overlap in molecular expression, these conspicuous dental defects are most likely the result of aberrant FGF signaling within the developing dentition and its surrounding tissues [40].

It remains unclear, however, whether the observed pattern of dental fluctuating asymmetry results from such pleiotropic effects. Because fluctuating asymmetry is a rather generic response to stress during development, we can only speculate as to whether the underlying cause of

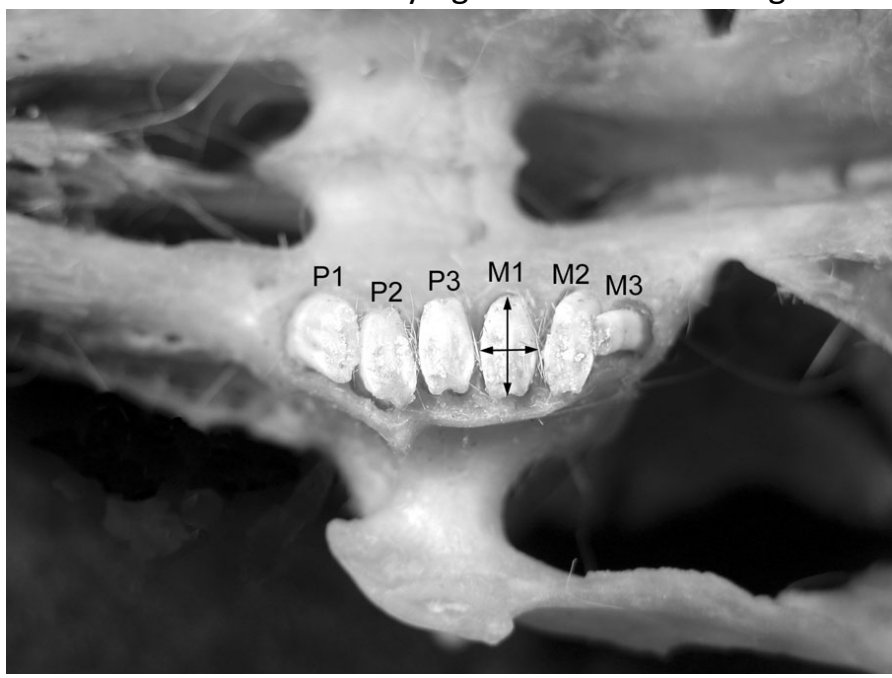

Figure 3. Inferior view of the rabbit skull showing the postincisor maxillary dentition (P1-M3) (first three premolars and molars). The arrows on M1 (first molar) represent the mesiodistal and buccolingual dimensions that were measured in the present study.

the fluctuating asymmetry is the same as that of the craniosynostosis. Dental dimensions have been shown to be highly heritable and are thought to be under relatively tight genetic control [59-61]. That being said, it is also clear that environmental influences such as local and systemic physiological factors, teratogens, and extra-organismic variables play a critical role in determining the final form and size of teeth, especially during the early stages of dental development $[62,63]$. Increased fluctuating dental asymmetry has been reported in a number of naturally and experimentally stressed human and nonhuman populations, although the source of the stress is sometimes not well defined [24, 27, 28, 64-70].

A number of possible explanations for the present findings may be offered. One possibility is that the same genetic mutation that causes premature suture fusion also results in increased dental fluctuating asymmetry. The genetic mutation in these rabbits has been identified recently as belonging to the fgfr family of genes working in tandem with a modifying gene (manuscript in preparation) so this may be a possibility; however, no obvious dental anomalies have been observed in this model, suggesting that overall dentogenesis is probably not affected in these rabbits. Accumulating evidence also suggests that altered calvarial bone regulation, resulting in hyperostosis and subsequent premature suture fusion in cases of nonsyndromic craniosynostosis, stems from localized, abnormal expression of various bone regulating growth factors (e.g., BMPs, FGFs, and/or TGF $\beta$ s) [1-3, 36]. Such abnormal growth factor expression may also primarily affect other developing antimeric osseous structures resulting in fluctuating asymmetry. However, DeLeon and Richtsmieir [38] reported no significant fluctuating asymmetry in the crania of 22 children with nonsyndromic sagittal synostosis, although the effects could have been ameliorated with age and remodeling. In addition, no significant changes in postcranial skeletal (e.g., first metacarpal) growth have been observed in synostotic rabbits [4145], although fluctuating skeletal asymmetry has not been examined yet and this mechanism remains a possibility.

Another possibility is that increased intracranial pressure resulting from premature suture fusion could invoke a generalized stress response by activating the hypothalamic-pituitary-adrenal axis, which may increase levels of fluctuating calcium during dentogenesis $[65,71]$, and secondarily result in increased dental fluctuating asymmetry in rabbits with early-onset synostosis. Increased fluctuating asymmetry has also been linked to external environmental stressors such as heat, cold and noise $[64,65,67]$. However, these factors are unlikely to play a major role in this study because all the rabbits in the present sample were raised under similar controlled, environmental conditions. It is also unlikely that functional wear effects account for these results since such effects are typically associated with directional asymmetries and should increase with age (no association between age and fluctuating asymmetry was observed). In addition, rabbit teeth are continually erupting and the lack of age related differences in dental fluctuating asymmetry suggest that the stress associated with craniosynostosis may be chronic in rabbits with early-onset synostosis. Finally, canalization of dental development may be under separate genetic control. Under this premise, less canalized organisms would be predisposed to manifesting elevated dental fluctuating asymmetry in the presence of deleterious factors, such as aberrant growth factor signaling. We recently reported 
a significant, negative relationship between coronal suture growth and the coefficient of inbreeding [46] in rabbits from this colony. Rabbits with early onset synostosis showed the least growth and greatest amount of inbreeding. It is possible that additional modifier genes accumulated from inbreeding were responsible for increased systemic stress and the increased levels of fluctuating dental asymmetry in these rabbits. Hueze et al. [72] also showed that human crania exhibiting a phenotypic continuum with skulls with bicoronal sutures synostosis displaying more intense asymmetry that skulls with unicoronal shape which supports this hypothesis.

Unfortunately, the present study was not designed to test these competing hypotheses. Fluctuating asymmetry is a subtle marker of developmental disturbance and its pervasiveness both in the craniodental complex and other anatomical regions of craniosynostotic organisms will need to be explored further in order to begin to unravel its biological basis. Given the numerous reports of various dental defects associated with syndromic craniosynostosis, it may be worthwhile to investigate other aspects of the dentition in nonsyndromic synostotic populations as well.

\section{Acknowledgements}

The authors would like to thank Kate Quinlin for her assistance in the lab. This work was supported in part by a grant from NIH/NIDCR (P60 DE13078).

\section{References}

1. Cohen MM (2000) History, terminology, and Classification of Craniosynostosis.
In: Cohen MM, MacLean

RE, editors. Cranio-

synostosis: Diagnosis, Eval-

uation, and Management.

New York: Oxford University Press. Pp. 1-20.

2. Opperman LA, Ogle RC (2002) Molecular studies of craniosynostosis: factors affecting cranial suture morphogenesis and patency. In: Mooney MP, Siegel MI, editors. Understanding Craniofacial Anomalies: the Etiopathogenesis of Craniosynostoses and Facial Clefting. New York: WileyLiss, Inc. 497-517 p.

3. Mooney MP, Cray JJ Jr, Losee JE, Moursi AM, Siegel MI, Cooper GM (2012) The development of molecular therapies for craniosynostosis. In: Schachner $\mathrm{P}$, editor. Proceedings of the 9th European Craniofacial Congress. Bologna Italy: Monduzzi Editore. Pp. 9-18.

4. Genetics of craniosynostosis: genes, syndromes, mutations and genotypephenotype correlations. Passos-Bueno MR, Serti Eacute AEAL, Jehee FS, Fanganiello R, Yeh E. Front Oral Biol. 2008;12:107-43. PMID: 18391498.

5. Prevalence and complications of single-gene and chromosomal disorders in craniosynostosis. Wilkie AOM, Byren JC, Hurst JA,
Jayamohan J, Johnson D, Knight SJL, Lester T, Richards PG, Twigg SRF, Wall SA. Pediatr. 2010; 126: e391-400. PMID: 20643727.

6. Prevalence of Pro250Arg mutation of fibroblast growth factor receptor 3 in coronal synostosis. Moloney DM, Wall SA, Ashworth GJ, Oldridge $M$, Glass IA, Francomano CA, Muenke M, Wilkie AOM. Lancet. 1997;349:1059-62. PMID: 9107244.

7. Craniosynostosis associated with FGFR3 Pro250Arg mutation results in a range of clinical presentations including unisutural sporadic craniosynostosis. Reardon W, Wilkes D, Rutland P, Pulleyn LJ, Malcolm S, Dean JCS, Evans RD, Jones BM, Hayward R, Hall CM. J Med Genet. 1997;34:6326. PMID: 9279753.

8. Identification of the first genetic cause for isolated unilateral coronal synostosis: a unique mutation in the fibroblast growth factor receptor 3 (FGFR3). Gripp KW, McDonaldMcGinn DM, Gaudenz K, Whitaker LA, Bartlett SP, Glat PM, Cassileth LB, Mayro R, Zackai EH, Muenke M. J Pediatr. 1998;132:714-6. PMID: 9580776.

9. Genetic study of nonsyndromic coronal cranio- 
synostosis. Lajeunie E, Le Merrer M, Bonaiti-Pellie C, Marchac D, Renier D. Am J Med Genet. 1995;55:5004. PMID: 7762595.

10. Genetic study of scaphocephaly. Lajeunie E, Le Merrer M, Bonaiti-Pellie C, Marchac D, Renier Am J Med Genet. 1996;62:2825. PMID: 8882788 .

11. From genotype to phenotype: the differential expression of FGF, FGFR, and TGF $\beta$ genes characterizes human cranioskeletal development and reflects clinical presentation in FGFR syndromes. Britto JA, Evans RD, Hayward RD, Jones BM. Plast Reconstr Surg. 2001;108:2026-39. PMID: 11743396.

12. Crouzonodermoskeletal syndrome. Jeftha A, Stephen L, Morkel JA, Beighton P. J Clin Pediatr Dent. 2004;28:173-6. PMID: 14969379.

13. A study of fluctuating asymmetry. Van Valen L. Evol. 1962;16:125-142.

14. Genetical control of stability in development. Mather K. Heredity. 1953;7:297336.

15. Canalisation of development and the inheritance of acquired characters. Waddington $\mathrm{CH}$. Nature. 1942;150:563-5.
16. Waddington $\mathrm{CH}$. (1957)The Strategy of the Genes. London: Allen and Unwin. $115 \mathrm{p}$.

17. Fluctuating asymmetry: $A$ biological monitor of environmental and genomic stress. Parsons PA. Heredity. 1992;68:361-364. PMID: 1563968.

18. Møller AP, Swaddle JP (1990) Asymmetry, Developmental Instability, and Evolution. Oxford: Oxford University Press. 56 p.

19. Markow TA (1994) Developmental Instability: its Origins and Evolutionary Implications. Dordrecht: Kluwer Academic Publishers. 102 p.

20. Polak M (2003) Developmental Instability: Causes and Consequences. Oxford: Oxford University Press. 87 p.

21. Developmental stability, disease and medicine. Thornhill R, Møller AP. Biol Rev Camb Philos Soc. 1997;72:497-548. PMID: 9375532.

22. Congenital cleft lip and fluctuating dermatoglyphic asymmetry. Woolf CM, Gianas AD. Am J Hum Genet. 1976;28:400-3. PMID: 941907.

23. A study of fluctuating asymmetry in the sibs and parents of cleft lip proposi- ti. Woolf CM, Gianas AD.

Am J Hum Genet. 1977;29:503-7. PMID: 900124.

24. Human tooth-size asymmetry in cleft lip with or without cleft palate. Sofaer JA. Arch Oral Biol. 1979;24:141-6. PMID: 299139.

25. Cleft lip with or without cleft palate and dermatoglyphic asymmetry: evaluation of a Chinese population. Neiswanger K, Cooper ME, Weinberg SM, Flodman $P$, Keglovitz $A B$, Liu $Y$, Hu DN, Melnick M, Spence MA, Marazita ML Orthod Craniofacial Res. 2002;5:140-6. PMID: 12194662

26. Down syndrome-a disruption of homeostasis. Shapiro B. Am J Med Genet. 1983;14:241-269. PMID: 6220605.

27. Fluctuating dental asymmetry: a measure of developmental instability in Down syndrome. Barden HS. Am J Phys Anthropol. 1980;52:169-173. PMID: 6445164.

28. Crown size asymmetry in males with fra $(\mathrm{X})$ or Martin-Bell syndrome. Peretz $B$, Ever-Hadani $P$, Casamassimo $P$, Eidelman E, Shellhart C, Hagerman R. Am J Med Genet. 1988;30:185-190. PMID: 2972204. 
29. Decreased developmental stability as assessed by fluctuating asymmetry of morphometric traits in preterm infants. Livshits $G$, Davidi L, Kobyliansky E, Ben-Amitai D, Levi Y, Merlob P. Am J Med Genet. 1988;29:793-805. PMID: 3400724.

30. Left-right asymmetries in embryonic development: a comprehensive review. Levin M. Mech Dev. 2005; 122:3-25. PMID: 15582774.

31. Attention-deficit hyperactivity disorder (AD/HD) and fluctuating asymmetry in a college sample: an exploratory study. Burton C, Stevenson JC, Williams DC, Everson ER, Trimble JE. Am J Hum Biol. 2003;15:60119. PMID: 12953172.

32. Anthropometric asymmetry in normal and mentally retarded males. Malina RM, Buschang PH. Ann Hum Biol. 1984;11:515-31. PMID: 6524867.

33. Fluctuating asymmetry and vertebral malformation: a study of palmar dermatoglyphics in congenital spinal deformities Goldberg CJ, Fogarty EE, Moore DP, Dowling FE. Spine. 1997;22:775-9. PMID: 9106319.

34. Psychological perspective on human developmental stability and fluctuating asymmetry: sources, applications and implications. Kowner R. Brit J Psychol. 2001;92:447-69. PMID: 11802884 .

35. Cohen MM. Sutural pathology (2000) In: Cohen MM, MacLean RE, editors. Craniosynostosis: Diagnosis, Evaluation, and Management. New York: Oxford University Press. $\mathrm{Pp}$. 51-68.

36. Transforming growth factor- $\beta$ isoform expression in the perisutural tissues of craniosynostotic rabbits. Poisson E, Sciote JJ, Koepsel R, Cooper GM, Opperman LA, Mooney MP. Cleft Palate Craniofac J. 2004;41:392-402. PMID: 15222795 .

37. Coronal suture pathology and synostotic progression in rabbits with congenital craniostenosis. Mooney MP, Smith TD, Langdon HL, Burrows AM, Stone CE, Losken HW, Siegel MI. Cleft Palate-Craniofac J. 1996; 33: 369-78. PMID: 8891367.

38. Fluctuating asymmetry and developmental instability in sagittal craniosynostosis. De Leon VB, Richtsmeier JT. Cleft Palate-Craniofac J. 2009; 46: 187-96. PMID: 19254065 .

39. Genotype, phenotype, and developmental biology of molar tooth characters.
Jernvall J, Jung HS. Am J Phys Anthropol. 2000;31(Suppl):171-190. PMID: 11123840.

40. Harris EF (2002) Dental development and anomalies in craniosynostoses and facial clefting. In: Mooney MP, Siegel MI, editors. Understanding Craniofacial Anomalies: the Etiopathogenesis of Craniosynostoses and Facial Clefting. New York: Wiley-Liss, Inc. Pp. 425-467.

41. Craniosynostosis with autosomal dominant transmission in New Zealand White rabbits. Mooney MP, Aston CE, Siegel MI, Losken HW, Smith TD, Burrows AM, Wenger SL, Caruso K, Siegel B, Ferrell RE. J Craniofac Genet Dev Biol. 1996;16:52-63. PMID: 8675615.

42. Development of a strain of rabbits with congenital simple, nonsyndromic coronal suture synostosis. Part II: Somatic and craniofacial growth patterns. Mooney MP, Losken HW, Siegel MI, Lalikos JF, Losken A, Burrows $A$, Smith TD. Cleft Palate Craniofac J. 1994;31:8-16. PMID: 8130248.

43. Development of a strain of rabbits with congenital simple, nonsyndromic coronal suture synostosis. Part I: Breeding demographics, 
inheritance pattern, and craniofacial anomalies. Mooney MP, Losken HW, Siegel MI, Lalikos JF, Losken A, Smith TD, Burrows $A$. Cleft Palate Craniofac J. 1994;31:1-7. PMID: 8130237.

44. A rabbit model of human familial, nonsyndromic unicoronal suture synostosis. Part I: Synostotic onset, pathology, and sutural growth patterns. Mooney MP, Siegel MI, Burrows AM, Smith TD, Losken HW, Dechant J, Cooper G, Kapucu MR. Childs Nerv Syst. 1998;14:236-246. PMID: 9694335.

45. Mooney MP, Siegel MI, Opperman LA (2002) Animal models of craniosynostosis: experimental, congenital, and transgenic. In: Mooney MP, Siegel MI, editors. Understanding Craniofacial Anomalies: the Etiopathogenesis of Craniosynostoses and Facial Clefting. New York: WileyLiss, Inc. Pp.251-272.

46. Genetic Homozygosity and Phenotypic Variability in Craniosynostotic Rabbits. Gilbert J, Cray JJ Jr, Kriethen A, Marazita ML, Cooper GM, Losee JE, Siegel MI, Mooney MP. Cleft Palate Craniofac J. 2017 Jan;54(1):94-9. PMID: 26882022.
47. Craniosynostosis: novel insights into pathogenesis and treatment. Wilkie AOM, Wall SA Curr Opin Neurol. 1996;9:146-52. PMID: 8782984.

48. Kieser JA (1990) Human Adult Odontometrics. Cambridge: Cambridge University Press. 237 p.

49. Palmer AR(1994) Fluctuating asymmetry analyses: a primer. In: Markow TA, editor. Developmental Instability: Its Origins and Evolutionary Implications. Dordrecht: Kluwer Academic Publishers. Pp. 335-64.

50. Fluctuating asymmetry: measurement, analysis, patterns. Palmer AR, Strobeck C. Annu Rev Ecol Syst. 1986;17:391-421.

51. Interobserver error in a large scale anthropometric survey. Gordon CC, Bradtmiller B. Am J Hum Biol. 1992;4:253-63. PMID: 28524349.

52. The oral manifestations of Apert syndrome. Kreiborg S, Cohen MM. J Craniofac Genet Dev Biol. 1992;12:41-48. PMID: 1572940.

53. Dental development in Apert syndrome. Kaloust S, Kazuhiro I, Vargervik K. Cleft Palate - Craniofac J. 1997;34:117-21. PMID: 9138505.
54. Oral manifestations of Crouzon's disease. Kelln EC, Chaudhry AP, Gorlin FJ.Oral Surg Oral Med Oral Pathol. 1960;13:1245-8. PMID: 13752352.

55. Partial anodontia of both the deciduous and permanent dentitions in a case of Crouzon's disease. Stein GM, Wahl H. Oral Surg Oral Med Oral Pathol. 1969;28:808-12. PMID: 5260651.

56. Natal molars in Pfeiffer syndrome type 3: a case report. Alvarez MP, Crespi PV, Shanske AL. J Clin Pediatr Dent. 1993;18:21-4. PMID: 8110608.

57. Pfeiffer syndrome: report of a family and review of the literature. Naveh Y, Friedman A. J Med Genet. 1976;13:277-80. PMID: 957376.

58. Evolution and development of teeth. McCollum MA, Sharpe PT. J Anat. 2001;199:153-9. PMID: 11385628.

59. Genetic covariance structure of incisor crown size in twins. Dempsey PJ, Townsend GC, Martin NG, Neale MC. J Dent Res. 1995;74:1389-98. PMID: 7560390.

60. Genetic analysis of deciduous tooth size in Australian twins. Hughes T, Dempsey $P$, Richards L, Townsend G. 
Arch Oral Biol.

2000;45:997-1004. PMID: 11000386.

61. Genetic and environmental contributions to variation in human tooth size. Dempsey P, Townsend GC. Heredity. 2001;86:685-93. PMID: 11595049.

62. The effect of environmental factors on tooth development: an experimental investigation. Riesenfeld A. Acta Anat (Basel). 1970;77:188-215. PMID: 5508460 .

63. Normal development of the jaws and teeth in pigs, and the delay and malocclusion produced by calorie deficiencies. Tonge $\mathrm{CH}$, McCance RA. J Anat. 1973;115:1-22. PMID: 4199500.

64. Fluctuating dental asymmetry and audiogenic stress. Siegel MI, Smookler HH. Growth. 1973;37:35-9. PMID: 4700428.

65. Heat stress, fluctuating asymmetry and prenatal selection in the laboratory rat. Siegel MI, Doyle WJ, Kelley C. Am J Phys Anthropol. 1977;46:121-6. PMID: 556888.

66. On the meaning of increased fluctuating dental asymmetry: a cross populational study. Doyle WJ, Johnston O. Am J Phys An- thropol. 1977;46:127-34.

PMID: 319679.

67. The effects of cold stress on fluctuating asymmetry in the dentition of the mouse. Siegel MI, Doyle WJ. J Exp Zool. 1975;193:385-9. PMID: 1176912.

68. Fluctuating asymmetry in molar dimensions and discrete morphological traits in Pima Indians. Noss JF, Scott GR, Potter RHY, Dahlberg AA. Am J Phys Anthropol. 1983;61:43745. PMID: 6624887.

69. Fluctuating dental asymmetry as a measure of odontologic canalization in man. Kieser JA, Groeneveld HT, Preston CS. Am J Phys Anthropol. 1986;71:43744. PMID: 3812659.

70. Comparison of fluctuating asymmetry level between normal and pathological specimens from modern Thai skeletal group. Jung $\mathrm{H}$, Woo EJ, Von CramonTaubadel N. Amer J Phys Anthropol. 2017; 162 (S64): 136.

71. Prenatal stress and increased fluctuating asymmetry in the parietal bones of neonatal rats. Mooney MP, Siegel MI, Gest TR. Am J Phys Anthropol. 1985;68:131-4. PMID: 4061598.
72. Unilateral and bilateral expression of a quantitative trait: Asymmetry and symmetry in coronal craniosynostosis. Heuzé Y, Martínez-Abadías N, Stella JM., Senders CW, Boyadjiev SA, Lo L-J, Richtsmeier JT. J Exp Zool B Mol Dev Evol. 2012; 318: 109-122. PMID: 22532473. 